\title{
Inhibition of the formation and stability of inorganic colloids in the alkaline disturbed zone of a cementitious repository
}

\author{
M. Felipe-Sotelo ${ }^{1, *}$, A. E. Milodowski ${ }^{2}$ and N. D. M. Evans ${ }^{1}$ \\ 1 Chemistry Department, Loughborough University, Loughborough LE11 3TU, UK \\ 2 British Geological Survey, Keyworth, Nottingham NG12 5GG, UK
}

[Received 3 November 2014; Accepted 3 March 2015; Associate Editor: Katherine Morris]

\section{ABSTRACT}

The generation and stability of inorganic colloids have been studied under hyperalkaline conditions. For the generation of colloids, intact cores of Bromsgrove Sandstone were flushed with simulated cement leachates, and the eluates were ultrafiltered sequentially $(12 \mu \mathrm{m}, 1 \mu \mathrm{m}, 0.1 \mu \mathrm{m}$ and $30 \mathrm{kDa})$ for the separation of any colloids found. No colloid formation was observed during the experiments; however the analysis by ICPMS of the eluates showed significant increases in Si and Al, indicating silicate mineral dissolution, as well as reduction of the concentration of $\mathrm{Ca}$ in the leachates indicating precipitation of secondary $\mathrm{Ca}$-rich phases. Flow experiments with cement leachates spiked with tritiated water showed a noticeable reduction of the porosity of the sandstone as well as changes in the pore distribution. Additional stability experiments were carried out using model silica and $\mathrm{Fe}_{2} \mathrm{O}_{3}$ colloids. The experiments indicated that the stability of the colloids was mainly controlled by the concentration of $\mathrm{Ca}$ in solution and that both types were unstable under the chemical conditions in the alkaline disturbed zone. The presence of cement additives such as superplasticisers could enhance the stability of the colloids.

Keywords: colloids, alkaline disturbed zone, silica, iron oxide.

\section{Introduction}

THE current concept for the disposal of intermediateand low-level waste in the UK involves the placement of grouted waste confined in steel canisters in a deep geological disposal facility (GDF). After closure, the mined vaults in the GDF will be backfilled with cementitious material that will contribute to the containment of radionuclides by a combination of chemical processes, namely solubility limitation, precipitation, co-precipitation and sorption (Nuclear Decommissioning Authority, 2010). While the cement will buffer the pore water

* E-mail: m.felipe-sotelo@lboro.ac.uk DOI: $10.1180 /$ minmag.2015.079.6.17 to a highly alkaline $\mathrm{pH}$, this could potentially create an alkaline plume penetrating from the repository into the host rock, perturbing the chemistry within a zone referred to as alkaline disturbed zone (ADZ). The alkaline cement leachate can react with the host rock, promoting dissolution of some mineral phases, precipitation of new phases (Daizères et al., 2010) and the generation of colloids (Mashal et al., 2004) that may affect radionuclide movement within the chemically disturbed zone of the host rock. The nature, stability and mobility of the colloids in the ADZ have been identified as sources of uncertainty in the performance assessment of a cementitious GDF (Swanton et al., 2009).

Swanton et al. (2009) carried out a review of the generation and behaviour of colloids under nearfield conditions; the authors concluded that in the
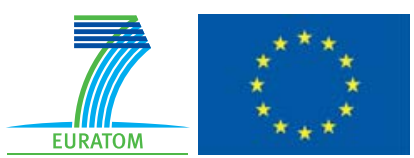

The publication of this research has been funded by the European Union's European Atomic Energy Community's (Euratom) Seventh Framework programme FP7 (2007-2013) under grant agreements $n^{\circ} 249396$, SecIGD, and $n^{\circ} 323260$, SecIGD2. 
presence of low concentrations of organic compounds the stability of the colloids would depend mainly on the ionic strength, and the high concentration of calcium in the pore water is expected to cause the destabilization of the colloidal particles. Although the cementitious colloids are thermodynamically unstable under low $\mathrm{pH}$ conditions, there is a lack of experimental evidence of their behaviour under ADZ conditions (Swanton et al., 2009, and references therein). Wetton et al. (1998) investigated the generation of colloids at Maqarin (Jordan), a natural analogue site, looking at the silica colloid production at the cement/host rock interface; from the small amount of material collected the authors suggested that the colloids in the interface had their origin in the cement zone. Another conclusion was that there were significant differences between the population and characteristics of the colloids found under laboratory conditions and those found at the natural analogue site. Several studies have investigated the formation of colloids from sediments in contact with the alkaline leachates from underground storage tanks in the Hanford Reservation (USA) in batch and column experiments (Flury et al., 2002; Mashal et al., 2004). Under flow conditions Flury et al. (2002) only observed significant mobilization of colloids when the ionic strength of the eluents was reduced from 1 to $10^{-3} \mathrm{~mol} \mathrm{dm}^{-3}$.

The aim of the present work is to study the generation of inorganic colloids from a generic host rock and the chemical changes induced in it by the advection of an alkaline plume through an intact

TABLE 1. The main mineral components of the Bromsgrove Sandstone.

\begin{tabular}{lc}
\hline Mineral component & Volume \%* \\
\hline Quartz & 76 \\
K feldspar & 16 \\
Illite/chlorite/smectite & 4 \\
Kaolinite & 3 \\
Muscovite & 1 \\
\hline
\end{tabular}

\footnotetext{
*Normalized after excluding porosity.

Trace amounts $(<1 \%)$ of albite, hematite, $\mathrm{TiO}_{2}$, zircon, biotite (or other Fe mica) and apatite were identified by detailed petrographic analysis but are below the level for SEM-EDX quantification.

No carbonate minerals (calcite, dolomite) were observed to be present in the sandstone.
}

rock core. Colloids can potentially increase the effective mobility of radionuclides, hence the importance of the study of colloid stability under ADZ conditions. The effects on colloid stability of diverse aspects of the chemistry of the cement leachates such as $\mathrm{pH}$ and $\mathrm{Ca}$ concentration will be assessed. Additionally, the effect of the presence of natural organic matter (humic acid), cement additives (superplasticisers) and cellulose degradation products from the waste packages will be also studied, as the presence of organics may increase the stability of colloids and therefore enhance their transport (Degueldre et al., 2000).

\section{Experimental}

\section{Testing colloid generation in intact sandstone under flow conditions}

For the study of colloid generation under the conditions of an alkaline disturbed zone (ADZ) a series of flow experiments were set up in which an intact core of sandstone was put into contact with a synthetic young cement leachate under dynamic conditions. The sandstone selected for this study was from the Bromsgrove Sandstone Formation of the Sherwood Sandstone Group (Hollington Sandstone Quarry, Hollington, Uttoxeter, Staffordshire). It was chosen as 'generic' quartzo-feldspathic rock with sufficient permeability to enable the laboratory flow experiments to be carried out on intact material. Intact rock with natural 'groundwateraged' mineral surfaces was preferred so as to avoid the experiments being influenced by reaction with fresh mineral surfaces, which would be the case if columns of crushed rock had been used. The main mineral components of this sandstone appear in Table 1.

The sandstone cores had $50 \mathrm{~mm}$ diameter and $100 \mathrm{~mm}$ length and the sides were coated with an impermeable epoxy resin so that the cement leachate could only pass through the ends. In order to reduce preferential flow paths, the solution was injected upwards into the sandstone cores, against gravity. A similar experimental set-up has been reported by Bryan et al. (2005). Two types of experiment were carried out; (i) intermittent contact of the cement leachates with the sandstone and (ii) continuous contact of the cement leachates with the rock at constant rate. The set-up for the first type of experiments has been adapted from the filtration rig used by Warwick et al. (2002). The cement leachate is contained in a reservoir under an $\mathrm{N}_{2}$-atmosphere and the pressure of $\mathrm{N}_{2}$ drives the solution from the 
container into the sandstone core and into the filtration rig for sequential ultrafiltration and removal of the colloidal particles. In this experiment the sandstone was intermittently in contact with the cement leachate over periods of $7-8$ hours, followed by stop-flow periods of 17-16 hours, during which filtration occurred. In the second type of experiment, the intact core of sandstone was pumped at constant flow $\left(50 \mathrm{~cm}^{3} \mathrm{~h}^{-1}\right)$ with a peristaltic pump inside a glove box under nitrogen atmosphere, and fractions of $2.5 \mathrm{dm}^{3}$ were collected in a reservoir and then sequentially filtrated. Four different sized membranes were used, $12 \mu \mathrm{m}$ (Whatman polycarbonate Cyclopore), $1 \mu \mathrm{m}$ (Whatman polycarbonate Nuclepore), $0.1 \mu \mathrm{m}$ and $30 \mathrm{kDa}$ (Amicon YM cellulose). After filtration, the excess of alkali solution was removed by applying a flow of $\mathrm{N}_{2}$ through the filtration rig for $1 \mathrm{~h}$; washing of the filters with deionized water was avoided since the changes in the composition or $\mathrm{pH}$ could potentially cause the re-dissolution of any of the collected colloids. The membranes were dried and kept in a glove-box in a $\mathrm{N}_{2}$-atmosphere before imaging of the surface by scanning electron microscopy (SEM). Phase identification under the SEM was based on qualitative chemical information obtained by energy-dispersive X-ray microanalysis (EDX) recorded simultaneously during SEM observation.

Throughout the experiments, aliquots of the leachate were sampled at the outlet of the sandstone cores and the main components of the solution were analysed by inductively coupled plasma mass spectrometry (ICP-MS, Agilent, 7700x Series, Stockport, UK) in semi-quantification mode before and after filtration with Whatman VecatSpin centrifuge filter tubes $(30 \mathrm{kDa} \mathrm{MWCO}$, polysulphone membrane). All samples, pre- and post-ultrafiltration, were acidified with $\mathrm{HNO}_{3}$ (TraceSELECT®Ultra from Fluka, Steinheim, Germany) before their analysis by ICP-MS. The changes in porosity caused by the flow of the alkaline fluid through the stone were also monitored by observation of the breakthrough curves of tritiated water (HTO, Perkin Elmer) through the core. For this purpose, the cement leachates were spiked with HTO $\left(20 \mathrm{~Bq} \mathrm{~cm}^{-3}\right)$ and pumped with a peristaltic pump at constant flow $\left(50 \mu 1 \mathrm{~min}^{-1}\right)$ through the rock; $1-1.5 \mathrm{~cm}^{3}$ aliquots were sampled with a fraction collector (Frac-920, GE Healthcare, Uppsala, Sweden) and mixed with $10 \mathrm{~cm}^{3}$ liquid scintillation cocktail (Gold Star Multipurpose Liquid scintillation cocktail, Meridian, Epsom, Surrey, UK) before measurement in the energy range between 0 and $18.6 \mathrm{kV}$ (TRI-CARB $2500 \mathrm{TR}$ Liquid Scintillation Counter, Packard).

\section{Stability of synthetic colloids}

The stability of colloids under the conditions of an ADZ was assessed in batch experiments using two model colloidal materials; silica (LUDOX ${ }^{\circledR}$ TM-50 colloidal silica, Aldrich, Steinheim, Germany) and $\mathrm{Fe}_{2} \mathrm{O}_{3}$ nanopartices (100 nm DLC particle size, Aldrich, Steinheim, Germany). $\mathrm{Fe}_{2} \mathrm{O}_{3}$ nanoparticles have been selected as a model of $\mathrm{Fe}$ colloids, as previous work regarding long-term rock alteration under ADZ conditions showed no evidence of the reduction of hematite (Moyce et al., 2014). In all the experiments, the colloid concentrations were $0.5 \mathrm{wt} . \%$ and $0.2 \mathrm{wt} . \%$ for silica and $\mathrm{Fe}_{2} \mathrm{O}_{3}$, respectively. Three series of experiments were carried out for both silica and $\mathrm{Fe}_{2} \mathrm{O}_{3}$ to assess the effect of $\mathrm{pH}$, in which increasing concentrations of either $\mathrm{NaOH}$ (laboratory reagent grade, $>98 \%$, Fisher Scientific) or $\mathrm{KOH}$ (analytical reagent grade, Fisher Scientific, Loughborough, UK) were added to the colloids suspensions in $0.01 \mathrm{~mol} \mathrm{dm}^{-3}$ $\mathrm{NaClO}_{4}$ (98\% extra pure, Acros Organics, Geel, Belgium) in the range between $10^{-6}$ and $10^{-1} \mathrm{~mol} \mathrm{dm}^{-3}$ or $\mathrm{Ca}(\mathrm{OH})_{2}$ (laboratory reagent grade, Fisher Scientific, Loughborough, UK) between $10^{-6}$ and $10^{-2} \mathrm{~mol} \mathrm{\textrm {dm } ^ { - 3 }}$.

The effect of the concentration of calcium on the stability of the colloids was determined by the addition of $\mathrm{Ca}$ in the range between $10^{-7}$ and $10^{-2} \mathrm{~mol} \mathrm{dm}^{-3}$ as $\mathrm{Ca}\left(\mathrm{NO}_{3}\right)_{2}\left(\mathrm{Ca}\left(\mathrm{NO}_{3}\right)_{2} \cdot 4 \mathrm{H}_{2} \mathrm{O}\right.$, for analysis, Fisher Scientific, Loughborough, UK) at pH $13\left(0.05 \mathrm{~mol} \mathrm{dm}^{-3} \mathrm{NaOH}+0.05 \mathrm{~mol} \mathrm{dm}^{-3}\right.$ $\mathrm{KOH})$. In order to mimic conditions such as intrusion of cement leachates in the host rock of the repository, experiments were performed in which increasing proportions of either young (YCL) or intermediate cement leachate (ICL) (see compositions in Table 2) were mixed with the suspensions of silica or $\mathrm{Fe}_{2} \mathrm{O}_{3}$ in $0.01 \mathrm{~mol} \mathrm{dm}^{-3} \mathrm{NaClO}_{4}$. The presence of organic compounds can also influence the stability of colloids; the organics could be already present in the host rock for example as humic acid (HA) and they could be carried by the alkaline plume, such would be the case of cement additives (superplasticisers) or be the result of the alkaline degradation of the cellulose in the intermediate and low-level waste (cellulose degradation products, CDP).

Thus, all the experiments were repeated in the absence of organic compounds as well as in either $5 \mathrm{ppm}$ of HA, $0.5 \%(\mathrm{w} / \mathrm{w})$ superplasticiser or $10^{-3} \mathrm{~mol} \mathrm{dm}^{-3}$ isosaccharinic acid (ISA, main 
TABLE 2. Composition of the artificial cement leachates.

\begin{tabular}{ll}
\hline $\begin{array}{l}\text { Young cement leachate } \\
\text { (YCL) }\end{array}$ & $\begin{array}{l}\text { Intermediate cement leachate } \\
\text { (ICL) }\end{array}$ \\
\hline $5.2 \mathrm{~g} \mathrm{dm}^{-3} \mathrm{KOH}$ & $0.296 \mathrm{~g} \mathrm{dm}^{-3} \mathrm{KCl}$ \\
$3.8 \mathrm{~g} \mathrm{dm}^{-3} \mathrm{NaOH}$ & $10 \mathrm{mg} \mathrm{dm}^{-3} \mathrm{NaCl}$ \\
$0.1 \mathrm{~g} \mathrm{dm}^{-3} \mathrm{Ca}(\mathrm{OH})_{2}$ & $1.2 \mathrm{~g} \mathrm{dm}^{-3} \mathrm{Ca}(\mathrm{OH})_{2}$ \\
$11.4 \mathrm{mg} \mathrm{dm}^{-3} \mathrm{NaHCO}$ & \\
$\mathrm{pH} 13.1$ & $0.37 \mathrm{mg} \mathrm{dm}^{-3} \mathrm{MgCl}_{2}$ \\
& $\begin{array}{l}0.5 \mathrm{mg} \mathrm{dm}^{-3} \mathrm{Na}_{2} \mathrm{CO}_{3} \\
\mathrm{pH} 12.3\end{array}$ \\
\end{tabular}

component of the CDP). Before use, the HA (Aldrich, Steinheim, Germany) had been purified following the procedure described by Kim et al. (1991). The sodium salt of ISA was produced inhouse by the synthesis procedure reported by Whistler and Be Miller (1963). ADVA ${ }^{\circledR}$ Cast 550 (Grace Construction products) was the cement additive selected as model of the behaviour of comb-type polycarboxylate superplasticisers. The stability of the colloid particles was assessed by means of the changes of intensity of the dynamic light scattering (DLS) signal as well as electrophoretic light scattering (ELS) (Zetamaster, Malvern Instrument Ltd, UK). DLS measurements were validated daily by the analysis of a Nanosphere ${ }^{\mathrm{TM}}$ size standard (polystyrene polymer, $216 \pm 4 \mathrm{~nm}$, Thermo Scientific). Samples were measured in polystyrene disposable cuvettes (Fisherbrand $^{\mathrm{TM}}$, Fisher Scientific) at an angle of $90^{\circ}$ to the incident beam $(670 \mathrm{~nm})$ and the multimodal method was used for the analysis of the correlograms. A zeta potential transfer standard ( $50 \pm 5 \mathrm{mV}$, Malvern Instrument Ltd, UK) was used for validation of ELS data. Single-factor ANOVA indicated that there were no significant differences $\left(\mathrm{F}=2.2186<\mathrm{F}_{\text {critical }}=2.6645\right)$ between the blank values with and without organic compounds; therefore the presence of a colloidal organic fraction in the liquid media could be discarded. All experiments were carried out in triplicate. Initial kinetic studies between 1 and 100 hours after the addition of the reagents to the colloidal suspensions indicated that no further changes in the stability of the colloids were observed after 18 hours; therefore all the results presented in the later section on the stability of synthetic colloids correspond to 18 hours. At the end of the equilibration time, $\mathrm{pH}$ values were also measured for all the suspensions using a semi-micro $\mathrm{pH}$ electrode provided by Fisher Scientific (Loughborough, UK) calibrated on a daily basis with buffers at $\mathrm{pH} 7.00$ (phosphate buffer), 10.01 (carbonate/bicarbonate) both provided by Thermo Scientific (The Netherlands) and $\mathrm{pH} 13.00$ (Reagecon, Ireland).

\section{Results and discussion}

\section{Sandstone alteration under flow conditions}

Generation of colloids and porosity changes

Of the six cores of sandstone treated with cement leachates under flow conditions, three of them blocked completely, and for the other three breakthrough and elution profiles of HTO could be obtained before and after the treatment with the alkaline solution. Initially the breakthrough of HTO occurs after the injection of $\sim 24 \mathrm{~cm}^{3}$ of spiked leachate, which would correspond to a volumetric porosity of $12 \%$. After treatment with YCL (approx. $12.5 \mathrm{dm}^{3}$ ) the breakthrough of HTO happens after the injection of only $8 \mathrm{~cm}^{3}$, which corresponds to a reduction of the overall porosity down to $4 \%$. After treatment with YCL the injection profile is more gradual, and it shows two slopes, which could indicate first rapid flow through preferential channels causing fast breakthrough of HTO and then slower flow into smaller pores. Petrographic analysis of the sandstone cores showed the localized formation of fine microporous secondary $\mathrm{C}(\mathrm{K}) \mathrm{SH}$ reaction products choking the primary intergranular porosity of the sandstone near the injection inlet of the core.

A total of 36 filters were observed by SEM and particles could only be found on the $12 \mu \mathrm{m}$ filters corresponding to the first fractions of YCL through the sandstone (between 2 and $2.5 \mathrm{dm}^{3}$ YCL through the core). The EDX analyses of these particles indicate the presence of significant amounts of $\mathrm{Si}$ and $\mathrm{Al}$. No $\mathrm{Fe}$ traces could be found in any of the particles analysed. However, further along the duration of the experiments (up to $10-12.5 \mathrm{dm}^{3}$ YCL were passed through the cores) no other $\mathrm{Si} / \mathrm{Al}$ particles could be found in any of the filters. This would suggest that these particles are formed not by chemical reaction of the YCL with the sandstone by dissolution and precipitation, but they may be due to physical dislocation or disaggregation of the finer particles within the sandstone. Similar results were obtained for both types of experiments under intermittent contact or constant flow. Few smaller particles could be observed on the $0.1 \mu \mathrm{m}$ and $30 \mathrm{kDa}$ filters, which presented very high concentrations of $\mathrm{Na}$ and $\mathrm{Ca}$. However, these particles were discounted as real 

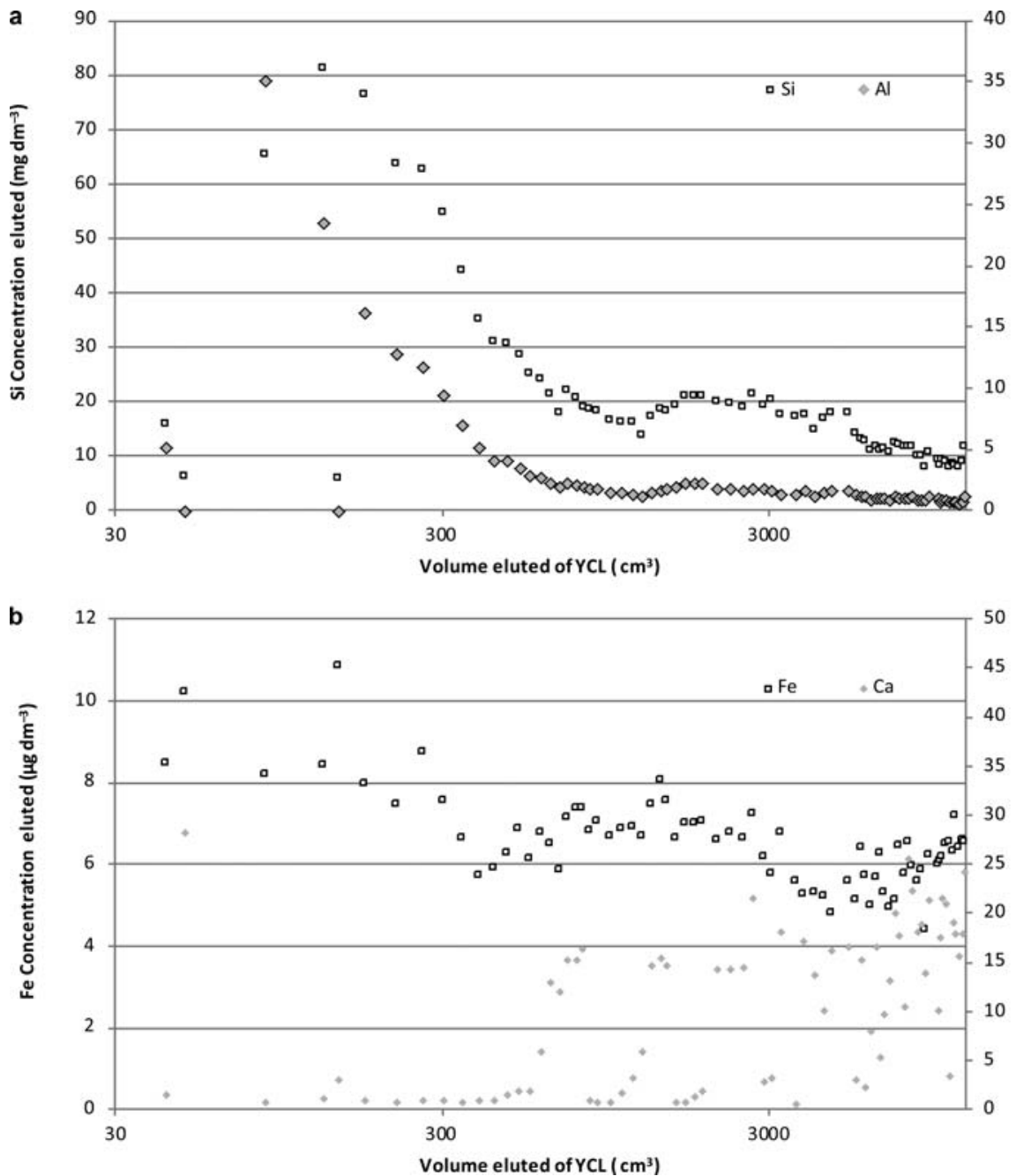

FIG. 1. Metal concentrations in the young cement leachate at the outlet of the intact sandstone cores $(a) \mathrm{Si}$ and $\mathrm{Al}$ and $(b)$ $\mathrm{Ca}$ and $\mathrm{Fe}$.

colloids formed by reaction with the sandstone, but they were considered to be artefacts resulting from the crystallization on the filters of traces of the YCL components. Therefore, it was concluded that under these experimental set-ups either no colloids were generated as result of the contact of YCL with intact sandstone under dynamic conditions, or colloids were formed but the chemical composition of YCL caused their precipitation within the sandstone fabric. To assess the latter hypothesis, batch studies with synthetic silica and $\mathrm{Fe}_{2} \mathrm{O}_{3}$ colloids were carried out (see results in the section on stability of synthetic colloids).

\section{Sandstone dissolution}

In addition to potential formation of colloids, the flow of cement leachates can induce the solubilization of some of the mineral components in the sandstone. Therefore, aliquots of the leachate at the outlet of the cores were analysed by ICP-MS in semi-quantitative mode. Figure $1 a$ shows the elution profiles of Si and $\mathrm{Al}$ in YCL, and as can be observed, both elements showed similar trends, with a sharp increase of the concentration within the first $100 \mathrm{~cm}^{3}$ of YCL through the core, reaching the maximum concentration (up to 35 and $80 \mathrm{mg} \mathrm{dm}^{-3}$ for $\mathrm{Al}$ and $\mathrm{Si}$, respectively) after 
$\sim 150 \mathrm{~cm}^{3}$ (around 6 pore volumes), followed by a gradual decrease of the concentrations and finally reaching stable values after $600 \mathrm{~cm}^{3}$ (25 pore volumes). The concentration of $\mathrm{Al}$ and $\mathrm{Si}$ detected by ICP-MS was similar for the samples pre- and post-ultrafiltration with $30 \mathrm{kDa}$ membranes; therefore it can be concluded that these two elements are present in solution in the eluted cement leachates and not as colloidal particles.

Other elements show similar trends to the one observed for $\mathrm{Al}$ and $\mathrm{Si}$, with most trace metals such as $\mathrm{Sr}, \mathrm{W}, \mathrm{Sn}, \mathrm{Pb}, \mathrm{Sb}, \mathrm{Ni}, \mathrm{V}, \mathrm{Co}, \mathrm{Cr}$ and $\mathrm{Cu}$ in the range of $\mu \mathrm{g} \mathrm{dm}^{-3}$, showing a sharp peak between 100 and $200 \mathrm{~cm}^{3}$ of YCL through the core. A few elements such as $\mathrm{Ba}$ and $\mathrm{Ga}$ showed a slow increase of the concentration in solution, up to $0.6 \mathrm{mg} \mathrm{dm}^{-3}$ and $20 \mu \mathrm{g} \mathrm{dm}^{-3}$ for $\mathrm{Ba}$ and $\mathrm{Ga}$ respectively, reaching stable values after $6000 \mathrm{~cm}^{3}$ of YCL.

Figure $1 b$ shows that there was very little dissolution of $\mathrm{Fe}$, and it was only detected in the eluted YCL at trace levels, between 5 and $12 \mu \mathrm{g} \mathrm{dm}^{-3}$. As for the other metals, Fe reached its maximum concentration in solution within the first 4 and 8 pore volumes, however, it did not show the sharp peak observed for $\mathrm{Al}$ and $\mathrm{Si}$.

The concentration of $\mathrm{Ca}$ in YCL (see composition in Table 2) is $54 \mathrm{mg} \mathrm{dm}^{-3}$, and as can be observed, the concentration in the eluted YCL was $50 \%$ or below the value at the inlet, in some cases below $1 \mathrm{mg} \mathrm{dm}^{-3}$, especially at the beginning of the experiment and it never reached its maximum concentration (Fig. 1b), despite the fact that the concentrations for the other elements had reached a steady state. Similar behaviour was observed in the flow experiments through Clashach sandstone carried out by Braney et al. (1993), where they observed retention of $24 \%$ (or higher) of the concentration of $\mathrm{Ca}$ at the inlet. Ramsay et al. (1991) performed leaching experiments using discs of OPC and St Bees sandstone under batch conditions, observing not only dissolution of $\mathrm{Al}$ and Si but also the deposition on the sandstone of Ca-rich particles. Therefore, despite the lack of colloids in the eluted YCL, these concentration profiles clearly show how the YCL causes dissolution of some of the mineral components of the sandstone on one hand, and on the other hand, the reduction in the concentration of $\mathrm{Ca}$ in the $\mathrm{YCL}$ could suggest precipitation of new mineral phases. The variation profiles observed in the present work for $\mathrm{Si}$ and $\mathrm{Ca}$ could be explained by the two-phase mechanism suggested by Usui et al. (2006), in which at the initial stage the silica particles offer a high surface area resulting in concentrations of dissolved Si higher than $\mathrm{Ca}$, and therefore all the $\mathrm{Ca}$ is removed from the leachate as $\mathrm{CSH}$ gel. As precipitation continues the surface area accessible for Si dissolution decreases, reducing the amount of silica in solution and the excess Ca elutes from the rock. In the present work, petrographic analysis of the sandstone cores showed the precipitation of fine CSH gel or microfibrous CSH locally within the pore network, which could account for the decrease in $\mathrm{Si}$ and $\mathrm{Ca}$ in solution.

\section{Stability of synthetic colloids}

The stability of colloids in ADZ is likely to be affected by the chemistry of the cement leachate; therefore in the present work the effects of $\mathrm{pH}$ and the concentration of $\mathrm{Ca}$ were studied. When assessing the effect of the $\mathrm{pH}$ on the stability of the colloids, it must be noted that due to the concentration of the background electrolyte $\left(0.01 \mathrm{~mol} \mathrm{dm}^{-3} \mathrm{NaClO}_{4}\right)$, the addition of concentrations of either $\mathrm{NaOH}, \mathrm{KOH}$ or $\mathrm{Ca}(\mathrm{OH})_{2}$ of $10^{-3} \mathrm{~mol} \mathrm{dm}^{-3}$ or higher (i.e. $\mathrm{pH} \geq 11$ ) causes a variation not only in the $\mathrm{pH}$ but also in the ionic strength of the solutions; therefore the changes in the stability of the colloids cannot be attributed uniquivocally to the $\mathrm{pH}$, but they might be the result of the combination of $\mathrm{pH}$ and ionic strength increases. The values shown in the figures in this section correspond to average $\pm \mathrm{SD}$ of three replicates.

\section{Effect of $\mathrm{pH}$}

Figures 2 and 3 present the effect of $\mathrm{NaOH}$ and $\mathrm{Ca}(\mathrm{OH})_{2}$ on silica and $\mathrm{Fe}_{2} \mathrm{O}_{3}$ colloids, respectively, and show that in general terms $\mathrm{Fe}_{2} \mathrm{O}_{3}$ colloids are more sensitive to changes in $\mathrm{pH}$ than silica. The light scattering data showed (Fig. $2 a$ ) precipitation of the silica colloids at concentrations of $\mathrm{NaOH}$ around $10^{-2} \mathrm{~mol} \mathrm{dm}^{-3}$ and $\mathrm{pH}$ values between 10 and 11 , while $\mathrm{Fe}_{2} \mathrm{O}_{3}$ seemed more affected by the presence of $\mathrm{NaOH}$, with noticeable reduction of the number of particles in solution from $\mathrm{pH} 7$ in $10^{-3} \mathrm{~mol} \mathrm{dm}^{-3} \mathrm{NaOH}$ (Fig. $3 a$ ); this point corresponded with a clear change on the surface charge of the $\mathrm{Fe}_{2} \mathrm{O}_{3}$ colloids from positive to negative, as shown by the Zeta potential data in Fig. $3 b$. Puls and Powell (1992) also reported a change in the

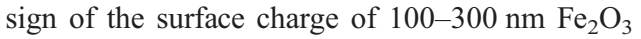
colloids in $\mathrm{NaClO}_{4}$ media between $\mathrm{pH} 6$ and 7 .

Moreover, there were no significant differences between the behaviour of silica in the presence and in the absence of organic compounds with increasing amounts of $\mathrm{NaOH}$, while for $\mathrm{Fe}_{2} \mathrm{O}_{3}$ the presence of $0.5 \% \mathrm{ADVA}^{\circledR}$ Cast 550 stabilized the 


\begin{tabular}{|cc|}
\hline$\bullet$ No organics & $\square$ Humic acid \\
$\triangle$ ISA & $\bullet$ ADVA-CAST \\
- pH (No organics) & $---p H$ (Humic acid) \\
$\cdots \cdots$ pH (ISA) & $-\cdot-\mathrm{pH}$ (ADVA CAST) \\
\hline
\end{tabular}
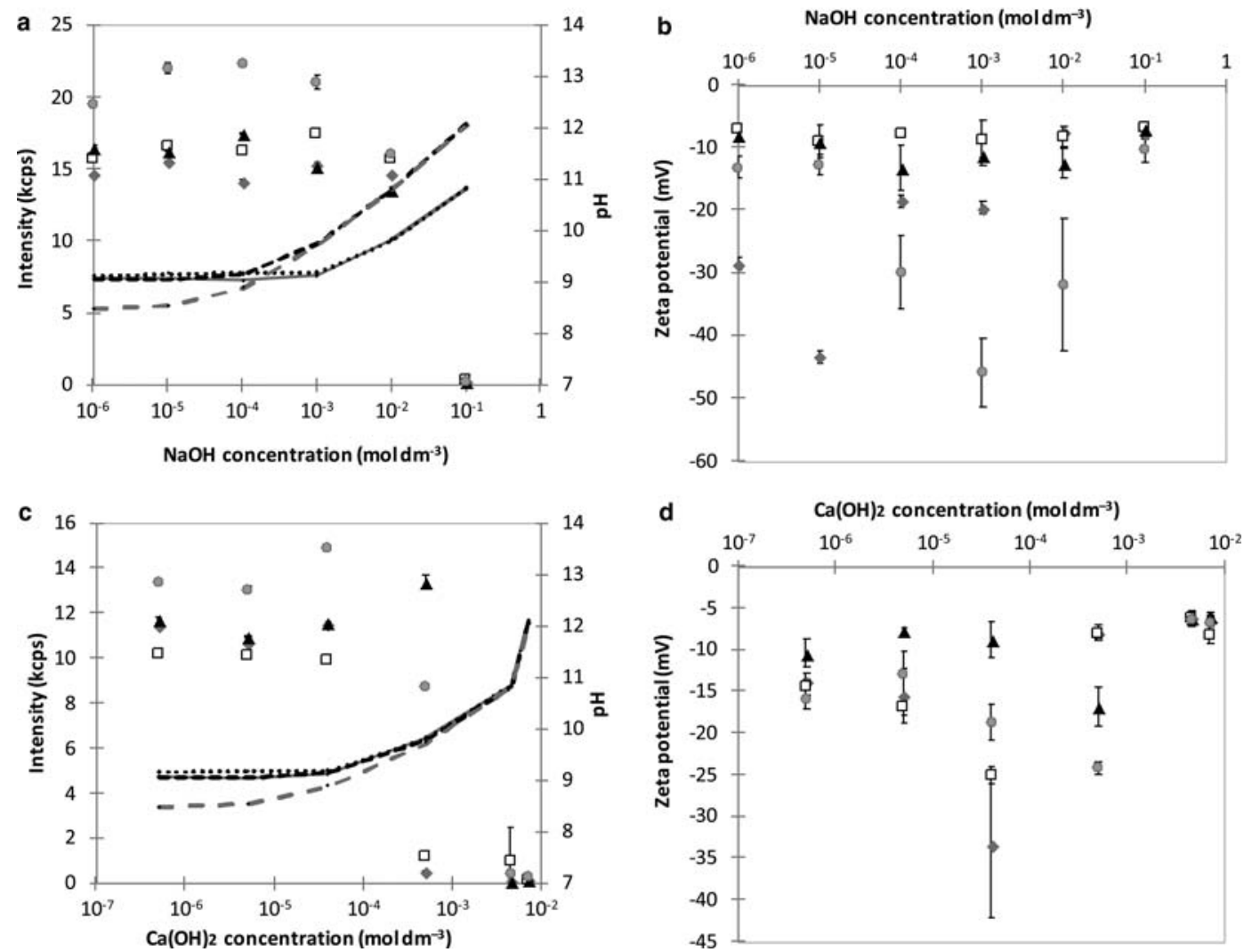

FIG. 2. Light scattering intensity and Zeta potential as a function of the $\mathrm{pH}$ for silica colloids in the presence of $\mathrm{NaOH}(a)$ light scattering and $(b)$ Zeta potential and in the presence of $\mathrm{Ca}(\mathrm{OH})_{2}(c)$ light scattering and $(d)$ Zeta potential.

colloids up to $\mathrm{pH} 12$. The Zeta potential data would suggest that the superplasticer absorb to the $\mathrm{Fe}_{2} \mathrm{O}_{3}$ colloids, making the charge on the surface of the colloids almost neutral; the addition of $\mathrm{NaOH}$ changes the Zeta potential to negative values; however this change was much more dramatic with no organics or with HA or ISA, than with $\mathrm{ADVA}^{\circledR}$ Cast 550.

When comparing the effect of $\mathrm{NaOH}$ (Fig. 2a) and $\mathrm{Ca}(\mathrm{OH})_{2}$ (Fig. $2 c$ ) on silica, it can be observed that the presence of $\mathrm{Ca}(\mathrm{OH})_{2}$ has a bigger destabilizing effect than $\mathrm{NaOH}$, and precipitation is observed from concentrations of $\mathrm{Ca}(\mathrm{OH})_{2}$ around $10^{-3} \mathrm{~mol} \mathrm{dm}^{-3}$, the same value as the one reported by Ramsay et al. (1991). The Zeta potential data for silica did not offer a clear picture of the effect of $\mathrm{NaOH}$ and $\mathrm{Ca}(\mathrm{OH})_{2}$ on silica colloids stability; in the presence of HA and ISA there was little variation of the Zeta potential, between -15 and $-5 \mathrm{mV}$, while in the other cases the oscillation of the potential was stronger, going down to -35 or $-45 \mathrm{mV}$. Ramsay et al. (1991) attributed the destabilization effect of $\mathrm{Ca}(\mathrm{OH})_{2}$ due to the sorption of $\mathrm{Ca}^{2+}$ ions to the silica surfaces, causing neutralization of the charge. However, in the present work, the Zeta potential measurements did not clearly support this hypothesis; furthermore, the oscillations of the Zeta potential values in the presence of $\mathrm{Ca}^{2+}$ and non-complexing ions $\left(\mathrm{Na}^{+}\right.$and $\left.\mathrm{K}^{+}\right)$were similar. An alternative 


\begin{tabular}{|c|c|}
\hline - No organics & Humic acid \\
\hline$\triangle$ ISA & - ADVA-CAST \\
\hline - $\mathrm{pH}$ (No organics) & $---\mathrm{pH}$ (Humic acid) \\
\hline$\cdots \cdots$ pH (ISA) & $-\cdot-\mathrm{pH}$ (ADVA CAST) \\
\hline
\end{tabular}
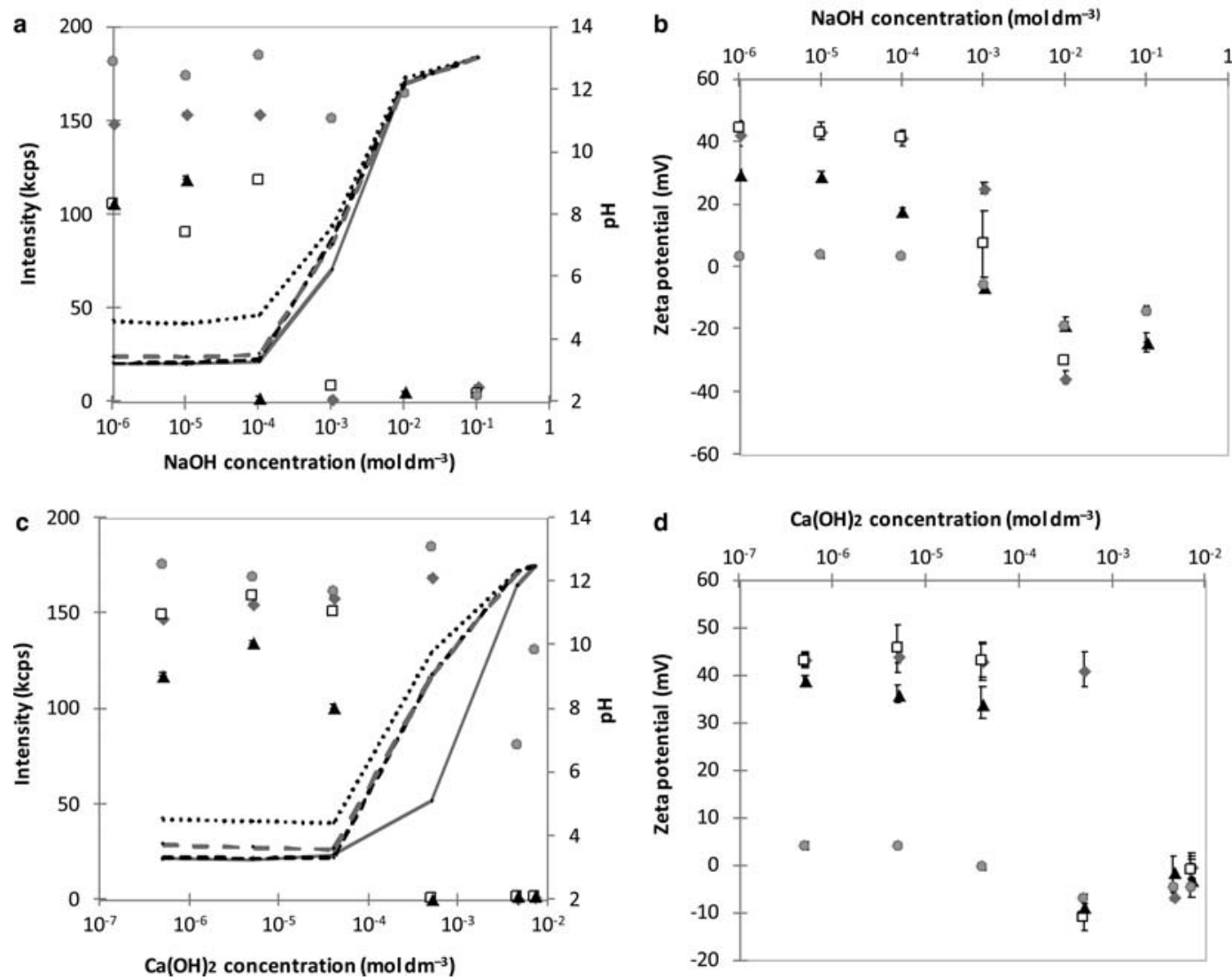

FIG. 3. Light scattering intensity and Zeta potential as a function of the $\mathrm{pH}$ for $\mathrm{Fe}_{2} \mathrm{O}_{3}$ colloids in the presence of $\mathrm{NaOH}$ (a) light scattering and $(b)$ Zeta potential and in the presence of $\mathrm{Ca}(\mathrm{OH})_{2}(c)$ light scattering and $(d)$ Zeta potential.

explanation of the effect of $\mathrm{Ca}(\mathrm{OH})_{2}$ would be the contraction of the electrical double layer of the negatively charged silica colloids (Ramsay, 1986; Ramsay et al., 1991), of which $\mathrm{Ca}^{2+}$ acts as counter ion.

Regarding $\mathrm{Fe}_{2} \mathrm{O}_{3}, \mathrm{Ca}(\mathrm{OH})_{2}$ caused precipitation of the colloids at a concentration around $5 \times 10^{-4} \mathrm{~mol} \mathrm{dm}^{-3}$ (Fig. 3c), a lower concentration than for $\mathrm{NaOH}$, which corresponded to a sharp change in the Zeta potential from $+50 \mathrm{mV}$ to negative values between -10 and $-2 \mathrm{mV}$ (Fig. $3 d$ ). This fits with the observations by Liang and Morgan (1990), who concluded that $\mathrm{Ca}$ is more effective than $\mathrm{Na}$ as a coagulant of $\mathrm{Fe}_{2} \mathrm{O}_{3}$ particles as can be qualitatively predicted by the Schulze-
Hardy rule (Nowicki and Nowicka, 1994). ADVA ${ }^{\circledR}$ Cast 550 stabilized the $\mathrm{Fe}_{2} \mathrm{O}_{3}$ colloids to higher concentrations of $\mathrm{Ca}(\mathrm{OH})_{2}$, keeping the Zeta potential of the colloids around neutral values. The addition of increasing concentrations of $\mathrm{KOH}$ between $10^{-6}$ and $10^{-1} \mathrm{~mol} \mathrm{dm}^{-3}$ had a similar effect to the one observed in the presence of $\mathrm{NaOH}$ for both silica and $\mathrm{Fe}_{2} \mathrm{O}_{3}$.

\section{Effect of Ca concentration at $\mathrm{pH} 13$}

Another aspect of the composition of the alkaline plume is the concentration of $\mathrm{Ca}$; therefore increasing concentrations of $\mathrm{Ca}$ (as $\left.\mathrm{Ca}\left(\mathrm{NO}_{3}\right)_{2}\right)$ in the range between $10^{-7}$ and $10^{-2} \mathrm{~mol} \mathrm{dm}^{-3}$ were 


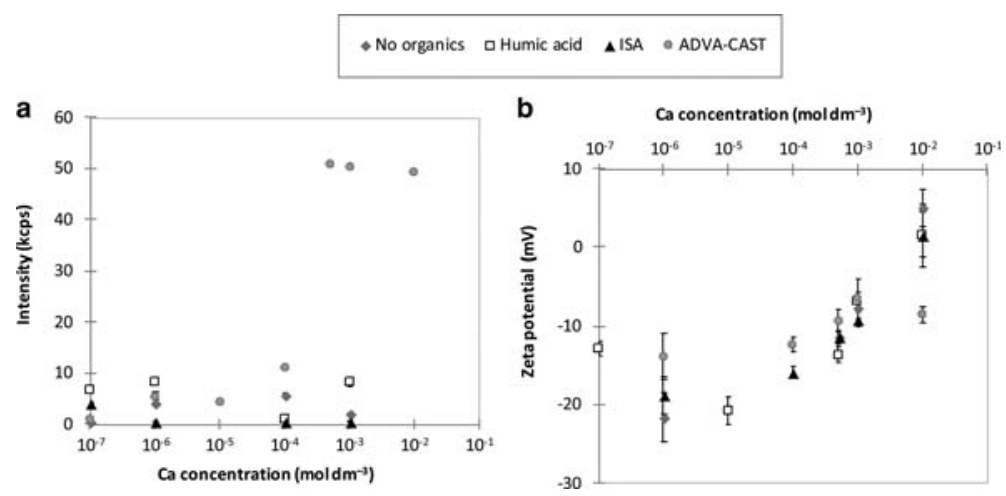

FIG. 4. Stability of $\mathrm{Fe}_{2} \mathrm{O}_{3}$ colloids as a function of the concentrations of $\mathrm{Ca}\left(\right.$ as $\left.\mathrm{Ca}\left(\mathrm{NO}_{3}\right)_{2}\right)(a)$ light scattering and $(b)$ Zeta potential.

added to silica and $\mathrm{Fe}_{2} \mathrm{O}_{3}$ in $0.05 \mathrm{NaOH}+$ $0.05 \mathrm{KOH} \mathrm{mol} \mathrm{dm}{ }^{-3}$ suspensions, mimicking the composition and $\mathrm{pH}$ of a fresh cement pore water. In the case of silica, the presence of Ca caused no further precipitation of the colloids and the Zeta potential remained almost constant around $-10 \mathrm{mV}$, and no differences were observed in the presence of organics. However, in the case of $\mathrm{Fe}_{2} \mathrm{O}_{3}$ (Fig. 4a), whilst at $\mathrm{pH} 13$ all colloids had precipitated, the presence of $\mathrm{ADVA}^{\circledR}$ Cast 550 caused the restabilization of $\mathrm{Fe}_{2} \mathrm{O}_{3}$ at concentrations of $\mathrm{Ca}$ higher than $10^{-3} \mathrm{~mol} \mathrm{dm}^{-3}$. At $\mathrm{pH} 13$, the addition of Ca caused a steady increase of the Zeta potential of $\mathrm{Fe}_{2} \mathrm{O}_{3}$ (Fig. $4 b$ ) going from $-25 \mathrm{mV}$ to positive values around $+5 \mathrm{mV}$, with the only exception of the experiments in the presence of $\mathrm{ADVA}^{\circledR}$ Cast 550 where the Zeta potential remained negative between -15 and $-10 \mathrm{mV}$ in the whole range of added $\mathrm{Ca}^{2+}$. This behaviour in the absence of an organic compound was also observed by Gardiner et al. (1992) who reported an increase in the Zeta potential value of hematite colloids in $10^{-3} \mathrm{~mol}$ $\mathrm{dm}^{-3} \mathrm{NaOH}$ as a result of the addition of cement leachates and specific sorption of $\mathrm{Ca}^{2+}$. In the present work, it would seem that $\mathrm{ADVA}^{\circledR}$ Cast 550 may be preventing the sorption of $\mathrm{Ca}^{2+}$ to the surface of the $\mathrm{Fe}_{2} \mathrm{O}_{3}$ colloids either by sorbing itself to the surface of the colloids or by complexation with $\mathrm{Ca}^{2+}$ and hence, limiting the amount of $\mathrm{Ca}^{2+}$ free to sorb to the colloids. It has been reported that in natural systems, the stability of iron oxides is controlled by humic substances (Tipping and Ohnstad, 1984). Tiller and O'Melia (1993) reported the increase in the stability of $\mathrm{Fe}_{2} \mathrm{O}_{3}$ colloids in the presence of two linear polyelectrolytes (poly (aspartic) and poly(acrylic) acid), used as models of natural organic matter (NOM) due to sorption to the particles under acid conditions and alteration of the net surface charge, stabilizing particles by electrostatic repulsion between negatively charged surfaces. However, the authors observed that even in the presence of NOM, $\mathrm{Ca}^{2+}$ caused destabilization of $\mathrm{Fe}_{2} \mathrm{O}_{3}$ by complexation with the anionic groups of the organic compounds and reducing the electrostatic repulsion that kept the colloids in solution (Mylon et al., 2004). In the present work, such stabilizing effects by humic acid could not be observed at $\mathrm{pH} 13$, since at this $\mathrm{pH}$ the net charge on the surface is negative as can be inferred from the Zeta potential data in Fig. $3 b$ and $d$, limiting the sorption of NOM to the colloids.

Gardiner et al. (1992) investigated the stability of model $\mathrm{Fe}_{2} \mathrm{O}_{3}$ colloids in Volvic water in the presence of $100 \mathrm{ppm}$ humic acid or the alkaline degradation leachate from wood with an equivalent organic content of $100 \mathrm{ppm}$ as total organic carbon (TOC), observing in both cases a noticeable increase in the stability of the colloids. Unfortunately, the authors did not provide data on the $\mathrm{pH}$ or the composition of the solutions; therefore it is difficult to compare these observations with the present work. However, it must be noted that the concentrations of humic acid and wood degradation products were higher than the ones used here (5 ppm HA and $10^{-3} \mathrm{~mol}$ $\mathrm{dm}^{-3}$ ISA, equivalent to $72 \mathrm{ppm}$ TOC). Moreover, Gardiner et al. (1992) attributed the stabilizing effect of the organic compounds to steric repulsion between sorbed organic layers on the surface of the hematite, while in the present work the Zeta potential data in Fig. $3 b$ and $d$ suggested that there was little (in the case of ISA) or no sorption of the organic compounds to the colloids, as the Zeta potential remained very close to the one in the absence of organic matter. 


\begin{tabular}{|cc|}
\hline \multicolumn{1}{|c}{ No organics } & $\square$ Humic acid \\
$\triangle$ ISA & $\bullet$ ADVA-CAST \\
- pH (No organics) & $---p H$ (Humic acid) \\
$\cdots \cdots \mathrm{pH}$ (ISA) & $-\cdot-\mathrm{pH}$ (ADVA CAST) \\
\hline
\end{tabular}
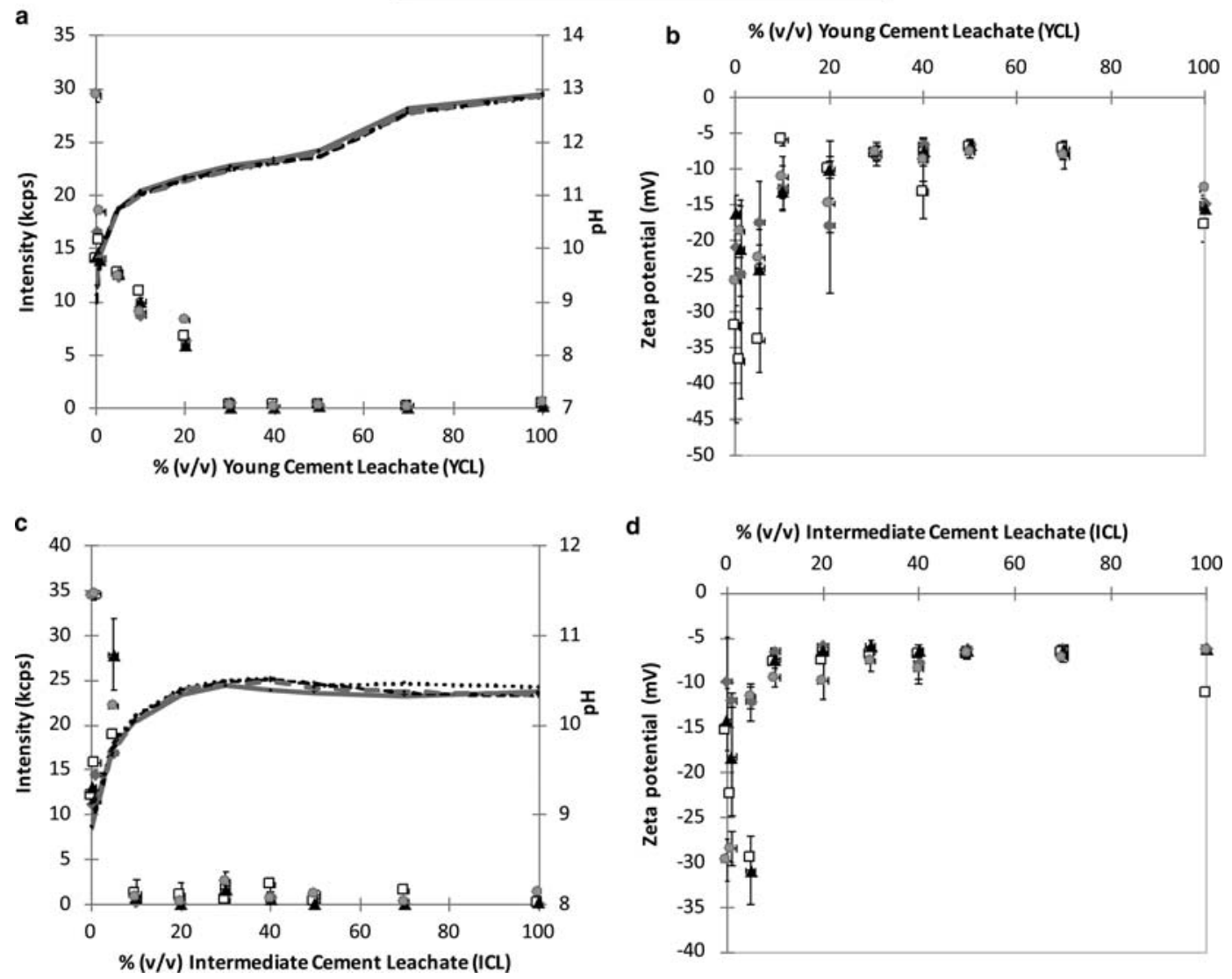

FIG. 5. Light scattering intensity and Zeta potential as a function of the percentage of cement leachate for silica colloids in the presence of YCL $(a)$ light scattering and $(b)$ Zeta potential and in the presence of ICL $(c)$ light scattering and $(d)$ Zeta potential.

\section{Addition of cement leachates}

In order to mimic a situation in which an intrusion of cement leachates reaches the colloids present in the host rock in the proximity of a cementitious repository, increasing proportions of either YCL or ICL were added to the silica and $\mathrm{Fe}_{2} \mathrm{O}_{3}$ in $0.01 \mathrm{~mol} \mathrm{dm}^{-3} \mathrm{NaClO}_{4}$. Figure 5 shows that the addition of YCL to the silica colloids caused a steady precipitation of the particles, which flocculate completely at percentages of YCL higher than $30 \% \mathrm{v} / \mathrm{v}$, and the effect of ICL is even more acute, with $10 \% \mathrm{v} / \mathrm{v}$ ICL causing complete precipitation of the colloids. The trends observed with the light scattering (Fig. $5 a$ and $c$ ) were mirrored by the Zeta potential data (Fig. $5 b$ and $d$ ), where the addition of the leachate modified the charge on the surface of the colloids from a Zeta potential around $-30 \mathrm{mV}$ to values between -10 and $-5 \mathrm{mV}$, and the ICL, which has a higher concentration of $\mathrm{Ca}^{2+}$, caused a faster change in the surface charge. This behaviour could be explained due to the sorption of $\mathrm{Ca}^{2+}$ to the silica. There were no differences observed in the behaviour of the silica colloids in the presence and absence of organic compounds, which may suggest the lack of affinity of the silica colloids for this type of organic compounds. The $\mathrm{Fe}_{2} \mathrm{O}_{3}$ particles 


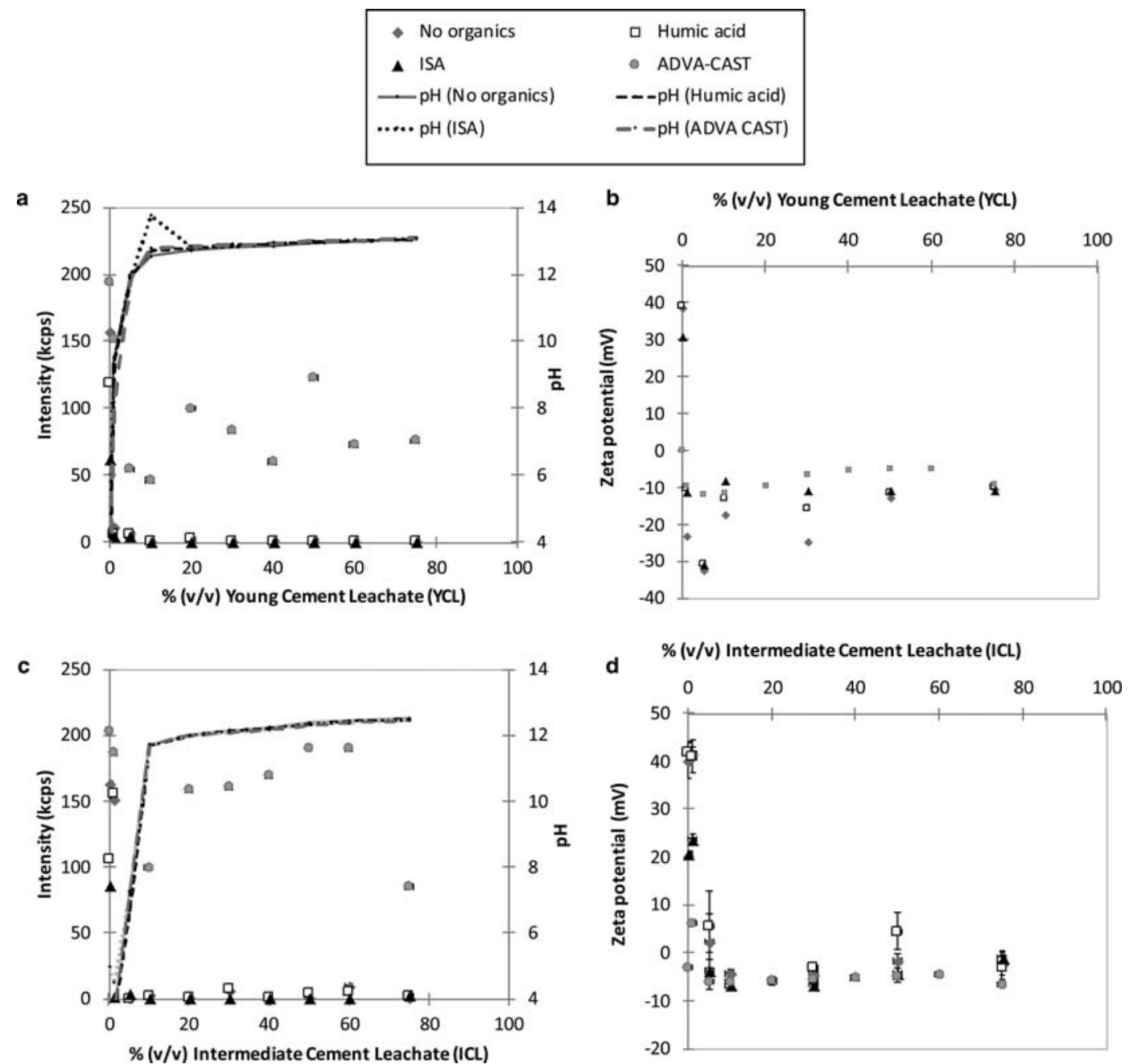

FIG. 6. Light scattering intensity and Zeta potential as a function of the percentage of cement leachate for $\mathrm{Fe}_{2} \mathrm{O}_{3}$ colloids in the presence of YCL $(a)$ light scattering and $(b)$ Zeta potential and in the presence of ICL $(c)$ light scattering and $(d)$ Zeta potential.

were more sensitive to the presence of YCL and ICL, and $1 \% \mathrm{v} / \mathrm{v}$ of any of the leaches was enough to cause complete precipitation of the colloids (Fig. 6). As in previous experiments $\mathrm{ADVA}^{\circledR}$ Cast 550 increased the stability of $\mathrm{Fe}_{2} \mathrm{O}_{3}$ in the presence of the cement leachates. Comparing Fig. $6 a$ and $c$, it can be observed that the extent of the $\mathrm{ADVA}^{\circledR}$ cast 550 stabilization effect was greater in the case of ICL than YCL, which may be related to the concentration of $\mathrm{Ca}^{2+}$ as suggested by the results in Fig. 4. $\mathrm{ADVA}^{\circledR}$ Cast 550 managed to maintain the Zeta potential of the $\mathrm{Fe}_{2} \mathrm{O}_{3}$ particles almost constant in the whole range of added YCL and ICL (Fig. $6 b$ and $d$ ), while in the other experiments the addition of the leachate very quickly changed the Zeta potential from a positive value between +20 and $+40 \mathrm{mV}$ to neutral or slightly negative potentials.

\section{Conclusions}

This work on the stability of model colloids, silica and $\mathrm{Fe}_{2} \mathrm{O}_{3}$, showed that under the conditions of the $\mathrm{ADZ}$, these colloids were very unstable and tended 


\section{FELIPE-SOTELO ETAL.}

to precipitate. This behaviour, seen under batch conditions, fitted with the observed lack of colloids generated from the treatment of sandstone cores with cement leachates under flow conditions. The stability of silica seemed to be more affected by the nature and concentration of the counter ions in solution, while the main factor governing $\mathrm{Fe}_{2} \mathrm{O}_{3}$ seemed to be the $\mathrm{pH}$. The presence of humic acid and ISA at the levels tested here did not affect the stability of the colloids under ADZ conditions; however the presence of the cement additive ADVA $^{\circledR}$ Cast 550 increased notably the stability of the colloids against the increase of $\mathrm{pH}$ and $\mathrm{Ca}$ concentration.

\section{Acknowledgements}

This work has been supported by the Natural Environment Research Council (NERC) through the Biochemical Gradients and RADionuclide transport BIGRAD project. A.E.M. publishes with the permission of the Executive Director of the British Geological Survey (NERC).

\section{References}

Braney, M.C., Haworth, A., Jefferies, N.L. and Smith, A. C. (1993) A study of the effects of an alkaline plume from a cementitious repository on geological materials. Journal of Contaminant Hydrology, 13, 379-402.

Bryan, N.D., Barlow, J., Warwick, P., Stephens, S., Higgo, J.J.W. and Griffin, D. (2005) The simultaneous modelling of metal ion and humic substance transport in column experiments. Journal of Environmental Monitoring, 7, 196-202.

Daizères, A., Le Bescop, P., Sardini, P. and Cau dit Coumes, C. (2010) Physico-chemical investigation of clayey/cement based materials interaction in the context of geological waste disposal. Cement and Concrete Research, 40, 1327-1340.

Degueldre, C., Triay, I., Kim, J.-I., Vilks, P., Laaksoharju, M. and Miekeley, N. (2000) Groundwater colloids properties: a global approach. Applied Geochemistry, 15, 1043-1051.

Flury, M., Mathison, J.B. and Harsh, J.B. (2002) In situ mobilization of colloids and transport of cesium in Hanford sediments. Environmental Science \& Technology, 36, 5335-5341.

Gardiner, M.P., Smith, A.J. and Williams, S.J. (1992) The effect of corrosion product colloids on actinide transport. AEA Technology report AEA-D\&D-237.

Kim, J.I., Buchau, G., Klenze, R., Rhee, D.S. and Wimmer, H. (1991) Characterisation and complexation of humic acids. CEC-report 13181.
Liang, L. and Morgan, J.J. (1990) Chemical aspects of iron oxide coagulation in water: Laboratory studies and implications for natural systems. Aquatic Sciences, 52, 32-55.

Mashal, K., Harsh, J.B., Flury, M. and Felmy, A.R. (2004) Colloid formation in Hanford sediments reacted with simulated tank waste. Environmental Science \& Technology, 38, 5750-5756.

Moyce, E.B.A., Rochelle, C., Morris, K., Milodowski, A. E., Chen, X., Thornton, S., Small, J.E. and Shaw, S. (2014) Rock alteration in alkaline cement waters over 15 years and its relevance to the geological disposal of nuclear waste. Applied Geochemistry, 50, 91-105.

Mylon, S.E., Chen, K.L. and Elimelech, M. (2004) Influence of natural organic matter and ionic composition on the kinetics and structure of hematite colloid aggregation: implications to iron depletion in estuaries. Langmuir, 20, 9000-9006.

Nowicki, W. and Nowicka, G. (1994) Verification of the Schulze-Hardy rule. Journal of Chemical Education, 71, 624-626.

Nuclear Decommissioning Authority (2010) Geological Disposal: Near-field Evolution Status Report. NDA Report NDA/RWMD/033.

Puls, R.W. and Powell, R.M. (1992) Transport of inorganic colloids through natural aquifer material: implications for contaminant transport. Environmental Science \& Technology, 26, 614-621.

Ramsay, J.D.F. (1986) Recent developments in the characterization of oxide sols using small angle neutron scattering techniques. Chemical Society Reviews, 15, 335-371.

Ramsay, J.D.F., Russell, P.J. and Avery, R.G. (1991) Colloids related to low level and intermediate level waste. AEA Technology report for the Department of Environment DoE/HMIP/RR/90/064.

Swanton, S.W., Alexander, W.R. and Berry, J.A. (2009) Review of the behaviour of colloids in the near field of a cementitious repository. Serco report to NDA RWMD SERCO/TAS/00475/01.

Tiller, C.L. and O'Melia, C.R. (1993) Natural organic matter and colloidal stability: models and measurements. Colloids and Surfaces A: Physicochemical and Engineering Aspects, 73, 89-102.

Tipping, E. and Ohnstad, M. (1984) Colloid stability of iron oxide particles from a freshwater lake. Nature, 208, 266-268.

Usui, H., Niibori, Y., Tanaka, K., Tochiyama, O. and Mimura, H. (2006) Effects of calcium in highly alkaline plume on permeability change of flow-path. Materials Research Society Symposium Proceedings, 932, 167-174.

Warwick, P., Allinson, S., Beckett, K., Eilbeck, A., Fairhurst, A., Russel-Flint, K. and Verral, K. (2002) Sampling and analyses of colloids at the Drigg low 


\section{COLLOIDS IN AN ALKALINE DISTURBED ZONE}

level radioactive waste disposal site. Journal of Environmental Monitoring, 4, 229-234.

Wetton, P.D., Pearce, J.M., Alexander, W.R., Milodowski, A.E., Reeder, S., Wragg, J. and Salameh, E. (1998) The production of colloids at the cement/host rock interface. In: Maqarin natural analogue study: Phase
III (J.A.T. Smellie, editor), SKB Technical Report TR98-04, SKB, Stockholm, Sweden.

Whistler, R.L. and Be Miller, J.N. (1963) Reactions of carbohydrates. Pp. 477-479 in: Methods in Carbohydrate Chemistry, Vol. 2 (M.L. Wolfrom and J.N. Be Miller, editors). Academic Press, New York. 